\title{
The Merits of Playing It by the Book: Routine versus Deliberate Learning and the Development of Dynamic Capabilities
}

\begin{abstract}
In this study, we investigate the nature of dynamic capabilities and use a fine-grained measurement to test how centralization, routinization, and formalization relate to the underlying learning components of dynamic capabilities. We find that the effects of centralization, routinization, and formalization are broadly similar for almost all components of dynamic capabilities, and that only a few show a different pattern. Centralization and routinization are negatively related to dynamic capabilities, formalization has a significantly positive effect. We provide insights into the role of managerial practices by explaining variation among the learning components of dynamic capabilities. This has implications for the nature and development of dynamic capabilities as well as for the routine versus deliberate learning debate.
\end{abstract}

Keywords: Dynamic Capabilities, Organizational Learning, Centralization, Routinization, Formalization, Structural Equation Modeling 


\section{Introduction}

Dynamic capabilities modify a firm's operating practices, orchestrate resource reconfiguration, and are crucial to sustaining competitive advantage in increasingly dynamic business environments (Teece, 2007; Teece et al., 1997; Teece et al., 2016). Dynamic capabilities rely heavily on accessing, sharing, and integrating knowledge (Helfat, 1997). They cannot be bought; they have to be built (Barreto, 2010). As such, dynamic capabilities are path-dependent and developed within the constraints of organizational systems (EasterbySmith and Prieto, 2008; Teece and Pisano, 1994). These systems together with managerial practices influence the degree of flexibility inherent in work processes, skills, and outputs (Mintzberg et al., 2005). In this study, we look at three dimensions of managerial practices: centralization, formalization, and routinization. Centralization, rules, and routines have long been seen as sources of inertia (Hannan and Freeman, 1984), protecting the status quo (Crozier, 1964). More recent research, however, has started to challenge these notions by pointing to the value that centralization, formalization, and routinization may have for decision-speed, learning, and change as new capabilities emerge and are retained throughout the organization (Baum and Wally, 2003; Feldman and Pentland, 2003). Routines may even be designed to promote or coordinate change (Argote and Guo, 2016; Becker et al., 2005; Nelson and Winter, 1982). It remains unclear why, from a learning perspective, managerial practices may either help or hinder the development of the dynamic capabilities.

We detect a clash of philosophies within the dynamic capabilities view. Looking at the literature on dynamic capabilities and learning, we identify some seemingly paradoxical ideas about different forms of organizational learning within dynamic capabilities research. First, organizational economists advocate the importance of routines for learning (Nelson and Winter, 1982). Routines are seen as the basis of capabilities, the 'genes' of firms, and a repository of organizational memory (Parmigiani and Howard-Grenville, 2011). For example, Levitt and March (1988, p. 319) theorize in detail on how firms learn by 'encoding inferences 
from history into routines.' However, Schreyögg and Kliesch-Eberl (2007) point out the inconsistencies of this view for dynamic capabilities as they argue that the reliability inherent in routines is at odds with the idea of continuous adaptation.

Second, organizational learning theorists emphasize the conflict between the incremental development of routines and the idea of deliberately driven learning mechanisms (Echajari and Thomas, 2015). Zollo and Winter (2002) argue that the articulation of rules, codification of knowledge, and other processes of deliberately capturing experiences are essential, yet underappreciated activities in developing dynamic capabilities. Codification of experience demands analysis of past experience, especially of cause-and-effect relationships between decisions and performance, in order to understand and articulate decision rules (Zollo and Winter, 2002). It also helps to diffuse existing knowledge throughout the organization (Kogut and Zander, 1992; Nonaka, 1994). These activities support the deliberate learning that may be necessary for developing dynamic capabilities. Accordingly, both routine-based learning and deliberate learning approaches are inherent in dynamic capabilities, however these approaches may also display constraints in the development of dynamic capabilities. In this study, we scrutinize this tension by investigating those dimensions which are key to routine and deliberate learning: centralization, routinization, and formalization.

We use a fine-grained instrument that covers the learning behaviors that underlie dynamic capabilities, ranging from recognizing early signals from the market to knowledge creation, integration, and monitoring activities. We account for the heterogeneity of dynamic capabilities and therefore look at different learning activities. This step is necessary as Teece (2007) suggests that dynamic capabilities may not have a coherent set of microfoundations, but could have one that is more diverse. In other words, dynamic capabilities research may benefit from a differentiated view on our three dimensions of managerial practices. We make conceptual and empirical contributions that add to the research on dynamic capabilities and the discussion about routine versus deliberate learning. 
First, we contribute to the debate on the nature of routines within the dynamic capabilities view. One camp advocates that learning is a routine-based construct; the other camp emphasizes deliberate learning as the primary source of adaptation (Echajari and Thomas, 2015). We develop both perspectives by looking at different managerial practices that expose the mechanisms of routine and deliberate learning. More specifically, we use routinization to identify what role routines play for the learning behaviors underlying dynamic capabilities. With formalization we see whether learning from previous experiences is integrated into a firm's knowledge repositories and used to develop rules and procedures that guide general problem solving. Centralization affects the locus of learning activities and helps us to understand where learning needs to occur in order for dynamic capabilities to thrive. Furthermore, exploring the role of routines within the dynamic capability view enables us to resolve one of the sources of concept specification issues of dynamic capabilities (Ambrosini and Bowman, 2009; Grant and Verona, 2015).

Second, Zollo and Winter (2002, p. 349) point out that little is known about how managerial practices interact with different learning activities. We develop theoretical and empirical insights about the linkages between centralization, routinization, and formalization and the learning components of dynamic capabilities. As these managerial practices affect middle managers across the SBUs studied and have an impact on collective learning in the organization, we develop complementary insights to dynamic capabilities research focusing on 'managerial cognitive capability' (Helfat and Peteraf, 2015), the quality of senior managers (Augier and Teece, 2009), and on managers' individual ability and decision-making (Teece et al., 2016). We examine whether the various learning behaviors that underlie dynamic capabilities benefit from different or similar managerial practices. At the same time, inspired by research that argues that the learning context (e.g., the complexity of problems) matters, we assess heterogeneous learning environments as we use a cross-industry sample 
(Argote, 1999). As a result, we expect to find out more about the degree of heterogeneity and about how different managerial practices relate to the components of dynamic capabilities.

Third, we contribute to the dynamic capabilities literature by providing both a measurement instrument and empirical evidence. Despite recent progress (e.g., Peteraf et al., 2013), the plethora of definitions of dynamic capabilities (Pisano, 2017) demands more work to arrive at a framework that captures the multidimensionality of the concept more parsimoniously. We address the lack of empirical evidence about dynamic capabilities, which can be attributed to their resistant nature "to observation and measurement" (Kraatz and Zajac, 2001, p. 653). Hence, there remains a black box that we try to open regarding the different learning components of dynamic capabilities and their drivers.

Our results based on a sample of German MNEs show that the underlying learning behaviors in dynamic capabilities form a rather homogeneous construct. The effects of centralization and formalization on the different components of dynamic capabilities are surprisingly consistent. Moreover, contrary to our hypothesis, the effect of formalization is consistently positive, providing evidence of the benefits of deliberate learning for creating and transferring new capabilities. We find less evidence suggesting that routine-based learning is crucial in developing the learning components of dynamic capabilities.

\section{Literature Review}

\section{Dynamic capabilities and learning}

Dynamic capabilities have been referred to as "the firm's ability to integrate, build, and reconfigure internal and external competences to address rapidly changing environments" (Teece et al., 1997, p. 516). This definition has been criticized as tautological or circular; it has been said to confound capabilities and abilities, and to mix firm and context characteristics (Zahra et al., 2006), and to lack a coherent theoretical basis (Arend and Bromiley, 2009). Zollo and Winter (2002, p. 340) trace the origins of dynamic capabilities to Selznick's (1957) pioneering notion of 'distinctive competences' and define dynamic 
capabilities as a "learned and stable pattern of collective activity through which the organization systematically generates and modifies its operating routines in pursuit of improved effectiveness." A learning- and knowledge-based conceptualization is advantageous in several regards, and serves as the basis for the theoretical development and empirical analysis in this paper. First, adopting the ensuing conceptualization follows the roots of the concept that are grounded in seminal research on organizational learning (Cohen and Levinthal, 1990; Kogut and Zander, 1992). Scholars in this domain (Bowman and Ambrosini, 2003; Teece et al., 1997) have alluded to learning processes underlying dynamic capabilities; these include knowledge acquisition, creation and sharing, as well as the recognition of new opportunities in the generation and modification of operating routines. As such, our proposed measure captures the multidimensional nature of dynamic capabilities. Second, dynamic capabilities are persistent, unlike operational capabilities which are ephemeral in nature. A disjointed one-off resource reconfiguration, however creative it may be, does not indicate dynamic capabilities (Zollo and Winter, 2002). Third, it allows a clear distinction to be made between basic operational routines and higher-order dynamic capabilities as these capabilities systematically orchestrate and operate the operational routines (Collis, 1994). Fourth, this definition avoids the tautological issue of defining a capability in terms of ability and does not suffer from theoretical roots that are ambiguous (Arndt and Pierce, 2017). Zollo and Winter's (2002) definition emphasizes the attributes 'stable pattern' and 'systematically modifying and generating routines' of dynamic capabilities. The definition is therefore well suited to guiding our inquiry into the nature of dynamic capabilities from both routine-based and deliberate learning perspectives.

The literature on learning has shown that different kinds of learning may have unique drivers, are integrated through different mechanisms, and may have different implications (Parmigiani and Granville-Howard, 2011). Learning may be deliberate using rules and agreements or may occur inadvertently (Teece, 2000). Much of the learning literature refers to 
learning from experience. Bingham and Eisenhardt (2011) argue that the transfer of experience from one context to another is difficult because it requires a deliberate effort to tailor lessons learned so that they can be used in a new context. This process involves creating and integrating new knowledge and possibly new capabilities. One issue with this idea is that a learning process of this kind relies on formalization as knowledge is packaged into new rules and procedures. Formalization in the sense of codified rules and knowledge sets has been identified as a source of inertia (Leonard-Barton, 1992, p. 118), because "deeply embedded knowledge sets actively create problems" by establishing "core rigidities". In contrast, Zollo and Winter (2002) argue that formalization only leads to inertia if it is done poorly. Formalization can add to the firm's knowledge base and as such serves as a potential driver of organizational learning (Cohen and Levinthal, 1990). This argument shows that the views on which drivers of learning lead to inertia and which to adaptation are anything but consistent.

Context in terms of complexity of decisions, prior experience, or the technology or partners involved might matter as well because learning and problem solving approaches may differ. Frequent and familiar situations are best addressed by routines as slight deviations can be easily detected and incorporated if necessary. Addressing learning from situations that are unfamiliar, rare, or very complex is more complicated, e.g. due to unclear cause-and-effect relationships and the need to draw on heuristics or integrate new information (Bingham et al., 2007). Within the dynamic capabilities view, situations of this type are of interest particularly when taking into account that dynamic capabilities are multi-level constructs (Gavetti, 2005; Teece, 2007). In situations which occur very infrequently, cannot be fully explained, or cannot easily be captured in a cause-and-effect relationship, routine-based learning is less likely to prove a successful means of capturing the learning as there may be little basis for developing routines. Instead, a more deliberate effort may be required to share, combine, and integrate knowledge from different domains in a more careful and structured manner. 


\section{Dynamic capabilities and managerial practices}

Starting with the basic premise that an organic structure is favorable for organizations to adapt to changing environments (Miles et al., 1978), possibly because it facilitates the development of dynamic capabilities within an organization, research has found mixed and sometimes contradictory results regarding how particular structural features and decision practices affect a firm's ability to adapt (Baum and Wally, 2003). Our approach enables us to extend the dynamic capabilities literature with detailed insights into how managerial practices drive routine-based and deliberate learning. The differences between these two kinds of learning may have contributed to the mixed findings.

Centralization. Centralization reflects the locus of decision-making authority (Dewar, et al., 1980; Pugh et al., 1968). Accordingly, we conceptualize centralization as the extent to which unit managers are free to make decisions without having to consult higher level managers. Baum and Wally (2003) show that a centralized strategic management fosters strategic decision speed, which is often argued to be a constituent part of dynamic capabilities (Barreto, 2010) and to influence the patterns of collective activity (Zollo and Winter, 2002). They argue that in times of virtual data processing, the advantages of decision-making at lower hierarchical levels are eroded. Due to efficiencies in information processing, it may be preferable to have centralized decision-making (Lin and Germain, 2003).

Conversely, high levels of centralization make it more difficult to spot opportunities because it restricts learning and information sharing among those at lower levels in the hierarchy (Laamanen and Wallin, 2009). Dynamic capabilities serve the "pursuit of improved effectiveness" (Zollo and Winter, 2002, p. 340) as they endow the firm with the "potential to systematically solve problems" (Barreto, 2010, p. 271). Nickerson and Zenger (2004) argue that simple and complex problems require different approaches. While simple problems can be solved efficiently by a single decision-maker and the resolution of conflict can best be enforced through hierarchy, complex problems are best solved by teams and consensus. 
Centralization can constrain the discussion of decision alternatives across hierarchical levels, reduce the collective awareness of the need to change, and lead to inertia and rigidity (Gilbert, 2005; King and Tucci, 2002). As such, if there is a high level of centralization, there is less likelihood of consensus due to information asymmetry. Moreover, centralization impedes the acquisition of knowledge outside the task environment because it imposes disincentives to search for new knowledge and integrate new experiences (Nickerson and Zenger, 2004). Distant know-how may be perceived as unproven or risky by superiors (Tushman and Anderson, 1986). As a consequence, opportunity recognition and knowledge acquisition are hampered, because centralization might make an organization more inclined to go for options that are more in line with their current practice, rather than those which are less familiar and less obvious (Moch and Morse, 1977). Furthermore, there is a concentration of information at the top of centralized organizations which can sometimes be excessive and may never reach those lower down the hierarchy (Wilensky, 1967). Centralization also constrains openness to new information and knowledge as it imposes informational limitations on decision-making at lower levels in the organization (Damanpour, 1991; Eggers and Kaplan, 2013). This in turn may lead to the emergence of silos of expertise within business units and to polarization of subgroups that do not share knowledge or integrate capabilities (Mooney et al., 2007).

Burgelman (1983) and Teece (2007) argue that decentralization is a precondition for developing dynamic capabilities. The Bay Area scholars provide evidence that the organizational change engine is fueled by "the autonomous strategic initiatives of individuals at the operational levels" (Burgelman, 1983, p. 241), and they underscore the value of decentralization for opportunity recognition and capability monitoring (Teece et al., 1997). Qualitative research suggests that decentralization can encourage organizations to learn from the process of sensing local opportunities and develop capabilities that are aligned to the local demands faced by business units (Fourné et al., 2014). Similarly, Rindova and Kotha (2001) 
show that decentralization was a key enabler for Yahoo! and Excite to successfully develop dynamic capabilities and an adaptive organization. Hence, we formally argue that:

Hypothesis 1: Centralization is negatively related to a firm's dynamic capabilities.

Routinization. Routinization refers to the extent to which work tasks are repetitive and invariable so that they require relatively little attention and consistent output is likely (Jansen et al., 2005; Withey et al., 1983). Routinization is reflected in the execution of repetitive tasks, usually in a fixed sequence, and in a predictable repertoire of behaviors. The repetitive nature of routines that may cause mindlessness (Ashforth and Fried, 1988), involve deskilling (Leidner, 1993), and thus can result in competency traps (Levinthal and March, 1993). Routinization undermines both the flexible learning behaviors and the adaptive processes that form the foundations of dynamic capabilities. The aim of routinization is to reduce uncertainty through rationalization (Mintzberg, 1979). This constrains the range of activities that are normally carried out and restricts the knowledge used, typically to what is already familiar. Moreover, routinization restricts interactions between organization members to those who are already familiar with each other (Daft and Macintosh, 1981) - and makes serendipitous encounters very rare. As such, routinization undermines the acquisition, sharing, and integration of new knowledge, activities which form a key pillar of dynamic capabilities.

However, there are exceptions in the literature that emphasize the adaptive nature of routines (e.g., Feldman and Pentland, 2003; Miner, 1990), and that recurring behavioral patterns may even promote change or enable flexibility. Argote and Guo (2016: 72) argue that "routines can contribute to an overall structure that enables flexible responses to new problems", and that the problem-solving works through "shared cognitive representation of the problem and enabled effective coordination." We acknowledge some ambiguity regarding the interpretation of routinization for adaptability. Given our relatively mature sample of MNEs, we follow Eisenhardt, Furr, and Bingham (2010) in that these organizations tend to 
seek efficiency from routinization. Hence, we focus in this hypothesis on the negative consequences of routinization.

Some scholars see routinization as contradicting the logic of dynamic capabilities as it may impede change and weaken the holistic approach needed to make good management decisions (Teece, 2007). It stands contrary to developing new skills and adopting new activities in day-to-day affairs. Traditionally, routines have been seen as a source of stability and inflexibility (Gersick and Hackman, 1990). While a frame-breaking approach such as dynamic capabilities requires flexibility and agility in changing behaviors and activity patterns in order to embrace opportunities (Schreyögg and Kliesch-Eberl, 2007), having a small range of well-honed and predefined routines limits the search for new knowledge and the potential absorptive capacity needed to make sense of novel experiences and integrate distant know-how (Ben-Menahem et al., 2013; Szulanski, 1996). Routines make absorptive capacity highly specialized and this makes it harder to learn from new challenges or experiences acquired from different strategic or industry contexts (Kor and Mesko, 2013). Consequently, routinization hampers the acquisition of knowledge outside the task environment and even makes it undesirable because knowledge acquisition is cumbersome and the consistency of outcomes is unlikely to be as high as with tasks that are highly routinized. Firms have to depart, at least to some extent, from existing routines in order to develop new capabilities (Brady and Davies, 2004). As Schreyögg and Kliesch-Eberl (2007) argued, routinization means programming, narrowing the scope, and reducing uncertainty, while dynamic capabilities require openness and flexibility.

Hypothesis 2: Routinization is negatively related to a firm's dynamic capabilities.

Formalization. We define formalization as the degree to which activities and relationships are governed by rules, procedures, instructions, and written records (Khandwalla, 1977; Rueckert et al., 1985). On the one hand, developing an organizational memory through codification alleviates to some extent the problem of tacit know-how and 
technical capabilities that are hard to share, recombine, and integrate (Galunic and Rodan, 1998; Hansen, 1999). Organizational knowledge may be embedded in rules and procedures (Teece, 2000). Formalization eases the search for and retrieval of knowledge (Lyles and Schwenk, 1992) and enhances the realized absorptive capacity by fostering an organizational memory (Jansen et al., 2005). Arguably, formalization facilitates experimentation as it makes activities and their linkages explicit (Foss, 2001). In what Adler and Borys (1996) call the enabling type of formalization, procedures and rules provide an organizational memory that serves to integrate and diffuse new capabilities. Moreover, using rules to formalize activities may reduce cognitive load and allows managers to channel their energy towards other more complex tasks (Kirschner, 2002).

On the other hand, the core issue regarding the role of formalization is that it inhibits the learning activities underlying dynamic capabilities and limits how far organizational activities may address change. Several scholars agree that formalization impairs the recognition and development of novel opportunities and creative solutions (Andrews and Smith, 1996; Damanpour, 1991). Written procedures and rules can never be exhaustive and deal effectively with all possible problems. High degrees of formalization hamper the generation of radically new ideas (Tushman and Anderson, 1986) and helps to ensure that individuals keep to established behaviors and activities (Weick, 1979); this is reinforced, for example, through the use of written records of performance (Malmi and Brown, 2008). This in turn reduces the likelihood of learning and developing novel skills by trial-and-error, which Zahra and colleagues (2006) deem to be crucial for the development of dynamic capabilities.

Furthermore, formalization provides frames of reference and narrow job descriptions which constrain exploratory efforts and direct attention towards a restricted range of behaviors (Jansen et al., 2005). Romme et al. (2011) find that more formal, rule-based human resource practices strengthen continuity and impede change. As such, formalization may be a source of inertia and inflexibility (Cyert and March, 1963). In the same way, formalization 
limits the scope and intensity of knowledge development. Indeed, formalization may make it challenging to acquire, exchange, and utilize new knowledge. Prieto and Easterby-Smith (2006) state that formalization of knowledge management reduces creativity. Furthermore, from an information-processing perspective it also inhibits knowledge sharing. Knowledge exchange and interactions that serve as a conduit for acquiring and assimilating competences become more difficult with higher degrees of formalization (Jansen et al., 2005).

Hypothesis 3: Formalization is negatively related to a firm's dynamic capabilities.

\section{Methods}

\section{Sample and data collection}

Teece and colleagues (1997) developed the idea of dynamic capabilities around multinational corporations. Following this idea, our sample focuses on large companies from ten industries, all headquartered in Germany. These industries range from automobiles, chemicals, consumer goods, and pharmaceuticals to IT, telecommunications, and transportation services. We chose this sampling for two reasons. First, as a nation known for its exports Germany has numerous highly developed and competitive industries that allow a sufficiently large sample size of large global firms. The high export orientation may also help us to argue that the results are generalizable in similar settings in other countries despite some idiosyncratic characteristics of the German context (Holm et al., 2010). A cross-industry study allows for more robust results. Deviation across industries serves as an indicator of the circumstances in which both the managerial practices and dynamic capabilities may take on a different shape (for example, in industries that are highly research-intensive or require high levels of capital expenditure).

We use the strategic business unit (SBU) as the level of inquiry for three reasons.

First, the corporate-level effects may have different sources and consequences (Adner and Helfat, 2003). Accordingly, we exclude corporate-level complementarities from the investigation. Second, SBUs are structured as firms, have separate legal status, and are able to make and execute decisions independently. Third, through initial interviews with SBU 
managers, we learned that they regard SBU as the appropriate level of analysis, because at this level opportunities are recognized, evaluated, and exploited through reconfiguration and integration of resources and competences. Our final sample includes companies with revenues of at least US\$100 million and 200 employees. It consists of 626 companies, with average revenues of US\$3.4 billion and 2,500 employees. The average age of an SBU was 27 years. We excluded SBUs that were less than 10 years old and focused on those operating throughout the year (Audretsch, 1991; Cabral and Mata, 2003). We use a survey design. The questionnaires were sent to at least two directors per business unit. Reminder emails were sent to increase the response rate. This process resulted in 265 SBUs from 179 companies returning the completed questionnaires. Over 90 percent of the respondents had general/middle management responsibilities or a commercial director function. Nine percent were technical directors. We calculated a mean of 13 years of professional experience and a four-year tenure in their current position for the respondents. A manager database confirmed the self-reported professional details (Batjargal, 2010).

\section{Measurement, validity, and reliability}

We used existing measures where appropriate. If not, we adapted existing measures following the suggestions in the literature regarding the development of scales (Mackenzie et al., 2011). The resulting items are based on seven-point Likert scales and are available in the appendix (see Table 2). Industry affiliation was dummy-coded. The perceptual measures we adopted are well accepted in strategic management research and have been extensively used in prior research (Agarwal and Selen, 2009; Danneels, 2008; Jansen et al., 2005).

Dynamic capabilities. Learning plays a central role in understanding dynamic capabilities (Zollo and Winter, 2002). We measure opportunity recognition with $\alpha=0.86$ (Danneels, 2008; Jansen et al., 2005; Jaworski and Kohli, 1993) and capability monitoring with $\alpha=0.87$ (Schreyögg and Kliesch-Eberl, 2007), knowledge acquisition with $\alpha=0.81$ (Jansen et al., 2005; Jaworski and Kohli, 1993), knowledge sharing with $\alpha=0.77$ (Collins and 
Smith, 2006; Jaworski and Kohli, 1993; Tippins and Sohi, 2003), knowledge creation with $\alpha=0.88$ (Pavlou and El Sawy, 2006), capability creation with $\alpha=0.90$ (Pavlou and El Sawy, 2006), and capability integration with $\alpha=0.87$ (Collins and Smith, 2006).

For the measurement of our overall construct of dynamic capabilities, we create a superordinate higher-order model (Edwards, 2001; see Figure 1). The components of dynamic capabilities co-vary significantly and support the assumption that there is a single underlying latent construct. All of our scales show a Cronbach's Alpha around or above the critical value of 0.7 with highly significant factor loadings (Shook et al., 2004). We use a number of fit indices for our models: $\chi^{2}$ /df, TLI, CFI, RMSEA, and SRMR (Schermelleh-Engel et al., 2003). The values for the second-order model are $\chi^{2} / \mathrm{df}=1.74, \mathrm{TLI}=0.95, \mathrm{CFI}=0.95$, RMSEA $=0.05$, and SRMR $=0.05$. We conclude that our model fits well with the data (Schermelleh-Engel et al., 2003).

--- Insert Figure 1 about here ---

Managerial practices. For all three dimensions of managerial practices we adopted scales used in prior research. Our scale for centralization $(\alpha=0.93)$ was operationalized with three items adopted from prior research (Dewar et al., 1980; Hage and Aiken, 1967). Routinization $(\alpha=0.91)$ consists of four items and was adapted from Jansen et al. (2005) and Withey et al. (1983). The four-item scale for Formalization $(\alpha=0.69)$ was also taken from existing research (Desphande and Zaltman, 1982; Jansen et al., 2005, 2006).

Control variables. We control for corporate support since the focus of this study is the SBU level (Adner and Helfat, 2003). We control for firm size (number of employees) and age (number of years the SBU has been operating). Our controls include industry variables that relate to medium- to high-velocity environments (Judge and Miller, 1991). We adopted Danneels' (2008) scale for slack resources $(\alpha=0.72)$. 


\section{Model validation}

Our method may be subject to common method bias (Podsakoff et al., 2012). We use second informants, archival data from annual reports, other company data and statistical methods to validate the responses of our respondents (Podsakoff et al., 2012). The results indicate that common method bias is unlikely to be a major concern.

Our overall assessment of conjoint model validation is displayed in Table 1. All items load on the assigned constructs only. We confirm the discriminant and convergent validity of the constructs by the Fornell-Larcker discriminant validity test with a confirmatory factor analysis (Fornell and Larcker, 1981; Hair et al., 2010). Further details regarding the methodology can be obtained from the authors.

--- Insert Table 1 about here ---

\section{Results}

Descriptive statistics and Pearson correlations for the variables in the study are exhibited in Table 2. We can observe a relatively high level of dynamic capabilities in the studied firms (similar to other studies about related constructs (Drnevich and Kriauciunas, 2011; Jansen et al., 2005)). This observation is surprising, yet not implausible as firms have to be able to learn and adapt in order to survive in the marketplace and given the context of MNEs from a highly developed nation. Results show significant negative correlations between centralization and dynamic capabilities as well as between routinization and dynamic capabilities. This evidence supports Hypotheses 1 and 2. Unexpectedly, we observe strong positive correlations between formalization and dynamic capabilities. Accordingly, Hypothesis 3 is not supported.

--- Insert Table 2 about here ---

For examining the hypotheses at the construct and dimension level (Wong et al., 2008), we constructed several structural models with centralization, routinization, and formalization as independent variables and with dynamic capabilities (Model A1), 
opportunity recognition (Model A2), capability monitoring (Model A3), knowledge acquisition (Model A4), knowledge creation (Model A5), knowledge sharing (Model A6), capability creation (Model A7), and capability integration (Model A8) as dependent variables. First, we included the control variables corporate support, slack resources, firm size, and firm age, and the industry dummies in all these models. As centralization, routinization, and formalization are expected to be interrelated and also depend on firm size, we assessed covariances between the respective constructs, which were freely estimated. Further, firm size, firm age, slack resources, and corporate support are not independent of each other. We accounted for these in the same manner. We removed all non-significant controls (Danneels, 2008). Figure 2 presents the standardized estimates of the main effects of Models A1 to A8.

--- Insert Figure 2 about here ---

Model A1 fits well with $\chi^{2} / \mathrm{df}=1.61, \mathrm{TLI}=0.92, \mathrm{CFI}=0.92, \mathrm{RMSEA}=0.05$, and $\mathrm{SRMR}=0.06$. Centralization has a very strong and negative effect $(-0.43 ; \mathrm{p}<0.001)$ on dynamic capabilities. Routinization shows a moderately strong negative influence on dynamic capabilities $(-0.27 ; \mathrm{p}<0.001)$. On the contrary, the effect of formalization on dynamic capabilities $(0.42 ; p<0.001)$ is positive and significant. Slack resources show an effect of 0.17 $(\mathrm{p}<0.05)$ on dynamic capabilities. Model A2 $(\chi 2 / \mathrm{df}=2.49, \mathrm{TLI}=.90, \mathrm{CFI}=.92, \mathrm{RMSEA}=.08$, and SRMR =.08) displays significant negative effects of centralization $(-.35 ; p<0.001)$ and routinization $(-.15 ; \mathrm{p}<0.05)$, and a significant positive effect of formalization $(.21 ; \mathrm{p}<0.01)$ on opportunity recognition. Further, slack resources $(.14 ; p<0.05)$ show a significant effect. Model A3 $(\chi 2 / \mathrm{df}=2.45, \mathrm{TLI}=.92, \mathrm{CFI}=.93, \mathrm{RMSEA}=.07$, and $\mathrm{SRMR}=.07)$ shows a significant negative effect of centralization $(-.27 ; \mathrm{p}<0.001)$ and a significant positive effect of formalization $(.34 ; \mathrm{p}<0.001)$ on capability monitoring. The effect of routinization on capability monitoring is negative, but not significant. Slack resources $(.17 ; \mathrm{p}<0.05)$ and chemicals/pharmaceuticals $(-.13 ; \mathrm{p}<0.05)$ show additional significant effects. Model A4 $(\chi 2 / \mathrm{df}=2.44, \mathrm{TLI}=.91, \mathrm{CFI}=.92, \mathrm{RMSEA}=.07$, and $\mathrm{SRMR}=.07)$ exhibits significant negative 
effects of centralization $(-.18 ; \mathrm{p}<0.05)$ and routinization $(-.35 ; \mathrm{p}<0.001)$ and a significant positive effect of formalization $(.23 ; \mathrm{p}<0.01)$ on knowledge acquisition. Corporate support $(.14 ; \mathrm{p}<0.05)$ and chemicals/pharmaceuticals $(-.15 ; \mathrm{p}<0.05)$ shows additional significant effects. Model A5 ( $\chi 2 / \mathrm{df}=2.37, \mathrm{TLI}=.92, \mathrm{CFI}=.94, \mathrm{RMSEA}=.07$, and $\mathrm{SRMR}=.07)$ reveals significant negative effects of centralization $(-.36 ; \mathrm{p}<0.001)$ and routinization $(-.33 ; \mathrm{p}<0.001)$ and a significant positive effect of formalization $(.38 ; \mathrm{p}<0.001)$ on knowledge creation. Slack resources $(.14 ; \mathrm{p}<0.05)$ and chemicals/pharmaceuticals $(-.12 ; \mathrm{p}<0.05)$ have additional significant effects. Model A6 ( $\chi 2 / \mathrm{df}=2.69, \mathrm{TLI}=.90, \mathrm{CFI}=.92, \mathrm{RMSEA}=.08$, and $\mathrm{SRMR}=.08)$ shows significant negative effects of centralization $(-.29 ; \mathrm{p}<0.001)$ and routinization $(-.21$; $\mathrm{p}<0.01)$ and a significant positive effect of formalization $(.31 ; \mathrm{p}<0.001)$ on knowledge sharing. Corporate support $(.14 ; \mathrm{p}<0.05)$, and computer/IT $(.21 ; \mathrm{p}<0.01)$ reveal additional significant effects. Model A7 $(\chi 2 / \mathrm{df}=2.84, \mathrm{TLI}=.91, \mathrm{CFI}=.93, \mathrm{RMSEA}=.08$, and $\mathrm{SRMR}=.07)$ shows significant negative effects of centralization $(-.40 ; \mathrm{p}<0.001)$ and routinization $(-.21$; $\mathrm{p}<0.001)$ and a significant positive effect of formalization $(.41 ; \mathrm{p}<0.001)$ on capability creation. Here only slack resources $(.14 ; \mathrm{p}<0.05)$ have additional significant effects. Model A8 $(\chi 2 / \mathrm{df}=2.92, \mathrm{TLI}=.91, \mathrm{CFI}=.93, \mathrm{RMSEA}=.08$, and $\mathrm{SRMR}=.07)$ displays significant negative effects of centralization $(-.38 ; \mathrm{p}<0.001)$ and routinization $(-.15 ; \mathrm{p}<0.05)$ and a significant positive effect of formalization $(.36 ; \mathrm{p}<0.001)$ on capability creation. Again, in addition only slack resources $(.13 ; \mathrm{p}<0.05)$ have significant effects. These results provide full support for hypotheses 1 and 2, but reject hypothesis 3 as a significant positive effect of formalization appears consistently across all models.

\section{Discussion}

In this study we investigate the relationship between different dimensions of managerial practices and different learning components of dynamic capabilities. We make several contributions that have implications for theory and practice - especially regarding learning perspectives and routines in dynamic capabilities research. First, we show that routine-based 
learning plays a minor role in the learning components of dynamic capabilities, but that deliberate learning as captured by formalization is important in developing dynamic capabilities. Second, this study inquires into the nature and drivers of different learning components of dynamic capabilities and expected some heterogeneity. However, we find the different learning components to be largely homogenous. Third, we develop and test a new measurement instrument for the learning components of dynamic capabilities in order to overcome the problems of measuring dynamic capabilities.

The impact of different dimensions of managerial practices on organizational activities such as learning and decision-making, and on performance has been subject to debate (e.g., Baum and Wally, 2003; Lin and Germain, 2003). Historically, managerial practices characterized by low degrees of centralization, routinization, and formalization has been considered to provide a competitive edge (Miles et al., 1978; Miller, 1988), possibly because it allows dynamic capabilities to emerge. Recently, Schmitt et al. (2015, p. 12) called for a better understanding of how organizational contingencies "may impact the pursuit of renewal" and adaptation. Using structural equation modeling this study provides more granular theorizing and analysis of managerial practice-capability models.

With respect to centralization and overall construct of dynamic capabilities, the results suggest that it is generally detrimental to a firm's dynamic capabilities. Baum and Wally's (2003) study suggests that centralization may have benefits for decision speed, due to more efficient information gathering and avoidance of organizational politics. However, decentralized decision-making processes and associated information disclosure may matter more for organizational learning activities. From this we suggest that there might be a tradeoff between decision speed and the fostering of learning that enables dynamic capabilities. On the basis of our findings and Nickerson and Zenger's (2004) notions that complex problems are best solved by teams and consensus, we recommend that senior managers should guide and control SBU activities, e.g. by utilizing different management control systems that 
provide boundaries, yet stimulate debate and leave autonomy within these boundaries (Malmi and Brown, 2008). Decentralization can be used as a lever to determine where learning takes place in the organization by providing incentives for gathering and evaluating information. This implies that simply going for rapid decision-making in top management may undermine learning at lower levels in the hierarchy. Thus, our results imply that greater decentralization can provide a stimulus for deliberate learning. The results also underscore the promise to consider middle management in such research endeavors in order to provide complementary insights to the roles and qualities of top management (e.g., Augier and Teece, 2009).

For both corporate and SBU managers we underscore the importance of understanding the trade-off between centralized decision-making and delegated decision-making across the corporate hierarchy because this decision affects the level at which dynamic capabilities will prosper. An extreme example might be Zappos, the U.S. shoe retailer that abolished traditional hierarchies to maximize the focus on customer service. It has a highly decentralized approach (adhocracy): Employees are given decision-making authority, yet bound in their decision-making by values that encourage change, growth, and learning so that customer needs can be better satisfied. While Zappos is currently successful in the market, it remains unclear whether such a system will enable the dynamic capabilities that will ensure the company's long-term survival. A question for future research is whether, in such environments, organizational learning at lower levels in the hierarchy will prove effective in the long run. Clues in this regard may be found in organizations such as Google or SAP that try to foster capability development by offering discretionary time (e.g., 'spend x percent of your time on personal initiatives') for new projects to emerge at across the hierarchy.

Next, the results of this study advance the deliberate learning perspective as they shed new light on the impact of formalization and how it could be leveraged. Our findings imply that formalization plays an important role, ranging from knowledge acquisition to retention processes that underlie dynamic capabilities. Prior studies have largely highlighted the 
restrictive and inflexible character of formalization, and we therefore expected it to have a negative impact on knowledge acquisition and assimilation (Jansen et al., 2005). In contrast, we find that formalization strengthens components of dynamic capabilities that relate to knowledge acquisition and capability development. These surprisingly consistent results imply that learning takes place through codifying, internalizing, and sharing prior experiences. The downside of limiting managers' cognitive frames (Jansen et al., 2005) may be outweighed by the benefits from making knowledge explicit and from making it easier to accrue and categorize knowledge.

Baum and Wally (2003) show the benefits of formalization for decision-making speed. We extend their notions by showing why decision-making speed is likely to improve with formalization. Clear procedures and transparency about job demands enable a firm to build an organizational memory. The role of organizational memory has been underestimated, especially in the case of non-routine activities in large established firms. Also these activities may be executed more easily when there are procedures or guidelines that reflect a firm's accumulated experience (Zollo and Winter, 2002). These procedures may facilitate the interpretation of external cues and information and eventually enable better decision-making. They may also be updated. In this sense, procedures and guidelines are abstractions of lessons learned from experience. Thus, they inform about what worked in the past and what may be useful for future problems, and thus make the leveraging of know-how scattered across the organization more effective. Overall, these insights support Zollo and Winter's (2002) notion that formalization, if done well, enables adaptation. They also show the value of deliberate learning that concurrently considers cognitive and behavioral elements in the development of dynamic capabilities.

Regarding the impact of routinization, the results show a negative relationship with most components of dynamic capabilities. This finding is insightful as it challenges the notion that routines (e.g., stable repetitive patterns) may foster dynamic capabilities. Repetitive work 
environments are not conducive to openness and creativity. The results suggest that routinebased learning may interfere with the acquisition and creation of knowledge, probably due to its frame-limiting nature. Identifying and understanding new developments early and being able to react to new cues, however, is core to dynamic capabilities and contrary to uniform activity patterns. Framed in organizational learning language (March, 1991), highly repetitive tasks are beneficial for exploitation, with strong self-reinforcing tendencies that are hard to break out of (Levinthal and March, 1993). In contrast, exploration to generate new knowledge is not associated with repetitive tasks, but rather with flexibility and chance encounters. Routinization, however, makes absorptive capacity highly specialized, which inhibits learning from new challenges and curtails the transfer of knowledge from one context to another (Kor and Mesko, 2013). This may be one reason why our results - taking into consideration our strict definition of routinization - show no indication of the adaptation and improvisation capacities that are argued by Feldman and Pentland (2003) to be embedded in routines. We acknowledge that some routines may foster learning and exploration through coordination, and by guiding new ways to solve problems or to make sense of external information (Argote and Guo, 2016). Comparing our results with the two previously referenced studies indicates that the relationship between routinization and different learning or adaptation activities is more complex and potentially depending on conceptualizations and contingencies.

Overall, as developing dynamic capabilities is not an automatic, routine-based process, the results imply that there is good news for practitioners in that they can actively shape dynamic capabilities by encouraging deliberate learning that draws on decentralized decisionmaking. Moreover, formalization potentially enables adaptation when it is used to guide learning and to structure decision-making. In this way, rules and procedures help build an organizational memory.

\section{The homogenous nature of dynamic capabilities}


Understanding the components of dynamic capabilities is an important addition to the literature, allowing scholars and practitioners to better grasp the heterogeneous nature of dynamic capabilities (Teece, 2007). Contrary to Teece's (2007) argument, we find quite similar patterns of results when we look at how each of the structural dimensions is linked to components of dynamic capabilities. This implies that the components of dynamic capabilities are rather homogenous and are affected by similar mechanisms, despite being of a different 'class' according to Teece (2007).

There could be two reasons for this finding. Either dynamic capabilities are largely homogenous in terms of how the underlying components work. This interpretation would support the perspective put forward by Eisenhardt and Martin (2000, p. 1105) who claim that dynamic capabilities are "more homogenous [...] than is usually assumed" and that they incorporate best practice. An alternative interpretation could be that we are drawing from a complementary set of components that has led to a relatively coherent measurement of dynamic capabilities. A complementary set of components would be influenced through largely similar mechanisms.

However, we are testing these conditions in a variety of industries, and thus in different contexts and probably different learning environments, given that different types and sources of knowledge are used in different industries. While our findings are largely robust across industries, we do find a few notable exceptions, particularly in those industries that are highly regulated. For example, in the banking and insurance sector, corporate support plays a bigger role in relation to dynamic capabilities, possibly because SBU renewal activities are subject to similar market regulations and constraints (Volberda et al., 2001). In the pharmaceutical industry, we discover that the role of capability monitoring is less important, possibly because benchmarking $\mathrm{R} \& \mathrm{D}$ activities is problematic, given the long development trajectories for new products and the inherently uncertain nature of the R\&D process. While the intensity of functional activities (e.g., R\&D budgets) can be monitored, benchmarking the 
quality of functional capabilities presents a particularly significant challenge in this industry. These examples show that while in most industries organizations feature similar sets of dynamic capabilities, the precise configuration varies across industries.

In the spirit of describing deviations from homogeneity across components of dynamic capabilities, we now focus on the individual learning components of dynamic capabilities. First, in line with our theorizing, opportunity recognition benefits from low levels of centralization. Business units cannot rely simply on a few individuals with concentrated decision-making authority. More promising is a system in which information is gathered and synthesized from a variety of sources within the organization to inform decision-making at lower levels. Our findings also indicate that opportunity recognition may entail some elements of information analysis (such as analyzing trade magazines or industry reports on a regular basis, etc.) that are relatively repetitive and do not change over time. This may explain the only modestly significant negative effect of routinization.

Moreover, formalization supports opportunity recognition. Understanding opportunities is a task that requires expertise and advanced cognition. (Baron and Ensley, 2006). Codifying know-how in the form of procedures and rules may provide a basis for recombining existing capabilities and integrating new knowledge (Galunic and Rodan, 1998; Zollo and Winter, 2002). Formalization may be conducive to opportunity recognition as it allows cognitive capacity to be channeled toward interpreting and integrating the information that has been collected. This is because formalization makes it easier to retrieve existing knowledge, relate new knowledge to it, and guide the search for new opportunities.

Capability monitoring benefits from decentralization. It is possible that capability monitoring is an infrequent or event-driven activity that follows known procedures (such as benchmarking), but requires the firm to consider shifting targets and associated changes in its capability portfolio. For example, finding the right key performance indicators for benchmarking and changing them in volatile environments is an art that demonstrates a firm's 
dynamic capabilities and may subsequently affect competitive advantage. Rules and procedures for how this benchmark selection is undertaken free up cognitive and managerial resources. Some functions may benefit from this more than others. For example, written records help the HR function in large established organizations to monitor the development of human capital and match the capability needs of different positions to the experience and skills available, while also considering individual career development objectives.

\section{Limitations and future research}

The results should be considered in the light of the study's limitations. The analysis is based on cross-sectional data, which allows to uncover the associations between constructs, but not the causal relationships. Dynamic capabilities are argued to alter the modus operandi of organizations (Teece et al., 2016). Thus, in the long run, once this modification is complete and has been fully accepted by all members of the organization, then managerial practices, or at least some aspects of them, may have changed as well. We recommend that future research should adopt a longitudinal research design that will enable researchers to discern the causality between the constructs.

Second, this study is set in the German context and the extent to which the learning activities underlying dynamic capabilities occur may be partially context dependent. That being said, the focal firms are large MNEs with a global mindset. They generate (perhaps because of their dynamic capabilities) a large share of their revenues outside of Germany. As such, alike Blome et al. (2013: 1314) we do expect "results to hold true in countries of similar development and industrialization”. Nonetheless, we recommend caution regarding the generalizability and recommend cross-context research. Such research could in the spirit of Holm et al. (2010) address wider sets of analytical questions (complementary to those at the managerial level of analysis) that are related to drivers of discretionary learning, and pay particular attention to the context in the research design. 
Third, we relied on established scales whenever possible, including the measurement instruments which have been used recently by others (e.g., Jansen et al., 2005, 2006). We acknowledge that the operationalization of the constructs may not be perfect; for instance, the scope and internal consistency of the formalization scale could be improved. It could be more precise about the codification processes. Also, the scale for routinization focuses perhaps too strongly on the repetitive nature of routines and could in future research incorporate the problem solving, coordinating nature of routines (Argote and Guo, 2016). Future studies may benefit from adopting scales that include a more holistic picture of the routines construct. Overall, we note that old scales may need updating in order to adequately capture state-of-theart managerial practices of contemporary organizations and the contexts in which they operate. The understanding of hierarchy, practices, and systems is in part culturally driven and does change over decades (Senge, 2014). Moreover, developments in information technology and data availability affect tasks and processes (Tallon and Pinsonneault, 2011) and allow for or even ask for practice updating. These factors change job profiles and demands and the associated decision processes that may have not been accounted for in the development of the original scales. To this end, we recommend the best practice put forward by MacKenzie et al. (2011) of assessing, and if necessary redeveloping, the scales that capture the managerial practices, and perhaps adapting the items for different contexts.

This study shows that dynamic capabilities are in general ubiquitous, but are heterogeneously distributed among firms. The broad idea is that dynamic capabilities enable the firm's operating routines and resources to be orchestrated and reconfigured (Augier and Teece, 2009; Teece, 2007; Teece et al., 2016). Given the insights provided by this study, the question of whether a firm has dynamic capabilities needs to be reformulated. While this study points to various ways in which managerial practices are linked to the dynamic capabilities underlying learning, opportunity recognition, and integration mechanisms, another key question remains: What level of dynamic capabilities should a firm possess for its 
business environment or industry context? This requires a reconsideration of the interplay between managerial practices, the environmental context, and firm or business unit performance. We suggest that these relationships may be explored using a configurational approach. Intriguingly, given the many possible configurations, a range of development paths may emerge from research that pays attention to contextual factors, because these are likely to influence both the paths themselves and the composition of dynamic capabilities within focal firms

In conclusion, in a research domain that has been accused of "conceptual inconsistencies and the lack of a coherent theoretical foundation" (MacLean et al., 2015: 340) and "endless debates about definitions" (Pisano, 2017: 747), this study not only develops a way to measure dynamic capabilities, but also provides fine-grained insights into how managerial practices constrain or enable the components of dynamic capabilities.

Three important points emerge from our study. First, when we compare the effects of routine-based and deliberate learning approaches in nurturing dynamic capabilities, what becomes clear is that deliberate learning is an essential part of this process. This helps to resolve an important issue surrounding the nature of dynamic capabilities and how they can be cultivated. Second, contrary to prevailing thinking, we found formalization to play a consistently positive role in terms of enabling the learning components which underlie dynamic capabilities. This finding echoes Zollo and Winter's (2002) notion of 'good' versus 'bad' formalization. When used well, formalization translates into generalized procedures and frameworks for action rather than narrow and prescriptive rules. Third, we find there to be significant commonalities in the way that the various learning components of dynamic capabilities work; there is much less variation here than one might have expected. This is somewhat surprising given the research by Teece (2007) and the different nature and stages of the learning components of dynamic capabilities. This finding has important implications for empirical perspectives on dynamic capabilities and for the idea of 'classes' within the 
dynamic capabilities view. In sum, this study provides a clearer understanding of the nature of dynamic capabilities and offers valuable insights into the advantages and disadvantages of routine-based and deliberate learning approaches.

\section{References}

Adler, P.S. and B. Borys (1996), 'Two types of bureaucracy: Enabling and coercive,' Administrative Science Quarterly, 41(1), 61-89.

Adner, R. and C.E. Helfat (2003), 'Corporate effects and dynamic managerial capabilities,' Strategic Management Journal, 24(10), 1011-1025.

Agarwal, R. and W. Selen (2009), 'Dynamic capability building in service value networks for achieving service innovation,' Decision Sciences, 40(3), 431-475.

Ambrosini, V. and C. Bowman (2009), 'What are dynamic capabilities and are they a useful construct in strategic management?' International Journal of Management Reviews, 11(1), 29-49.

Andrews, J. and D.C. Smith (1996), 'In search of the marketing imagination: Factors affecting the creativity of marketing programs for mature products,' Journal of Marketing Research, 33(2), 174-187.

Arend, R. and P. Bromiley (2009), 'Assessing the dynamic capabilities view: spare change, everyone?' Strategic Organization, 7(1), 75-89.

Argote, L. (1999), Organizational learning: Creating, retaining and transferring knowledge. Kluwer Academic: Boston, MA.

Argote, L. and J.M. Guo (2016), 'Routines and transactive memory systems: Creating, coordinating, retaining, and transferring knowledge in organizations,' Research in Organizational Behavior, 36, 65-84.

Arndt F. and L. Pierce (2017), 'The behavioral and evolutionary roots of dynamic capabilities', Industrial and Corporate Change, Advance Access published 10 November 2017: https://doi.org/10.1093/icc/dtx042.

Ashforth, B.E. and Y. Fried (1988), 'The mindlessness of organizational behaviors,' Human Relations, 41(4), 305-329.

Audretsch, D.B. (1991), 'New-firm survival and the technological regime,' The Review of Economics and Statistics, 73(3), 441-450.

Augier, M. and D.J. Teece (2009), 'Dynamic capabilities and the role of managers in business strategy and economic performance,' Organization Science, 20(2), 410-421.

Barreto, I. (2010), 'Dynamic capabilities: A review of past research and an agenda for the future,' Journal of Management, 36(1), 256-280.

Batjargal, B. (2010), 'The effects of network's structural holes: polycentric institutions, product portfolio, and new venture growth in China and Russia,' Strategic Entrepreneurship Journal, 4(2), 146-163.

Baum, J.A.C. and S. Wally (2003), 'Strategic decision speed and firm performance,' Strategic Management Journal, 24(11), 1107-1129. 
Becker, M. C., N. Lazaric, R.R. Nelson and S.G. Winter (2005), 'Applying organizational routines in understanding organizational change,' Industrial and Corporate Change, 14(5), 775-791.

Ben-Menahem, S.M., Z. Kwee, H.W. Volberda and F.A.J. Van Den Bosch (2013), 'Strategic renewal over time: the enabling role of potential absorptive capacity in aligning internal and external rates of change,' Long Range Planning, 46(3), 216-235.

Bingham, C.B. and K.M. Eisenhardt (2011), 'Rational heuristics: the 'simple rules' that strategists learn from process experience,' Strategic Management Journal, 32(13), 1437-1464.

Bingham, C.B., K.M. Eisenhardt and N.R. Furr (2007), 'What makes a process a capability? Heuristics, strategy, and effective capture of opportunities,' Strategic Entrepreneurship Journal, 1(1-2), 27-47.

Blome, C., T. Schoenherr and D. Rexhausen (2013), 'Antecedents and enablers of supply chain agility and its effect on performance: a dynamic capabilities perspective,' International Journal of Production Research, 51(4), 1295-1318.

Bowman, C. and V. Ambrosini (2003), 'How the resource-based and the dynamic capability views of the firm inform corporate-level strategy,' British Journal of Management, 14(4), 289-303.

Brady, T. and A. Davies (2004), 'Building project capabilities: From exploratory to exploitative learning,' Organization Studies, 25(9), 1601-1621.

Burgelman, R.A. (1983), 'A process model of internal corporate venturing in the diversified major firm,' Administrative Science Quarterly, 28(2), 223-244.

Cabral, L.M. and J. Mata (2003), 'On the evolution of the firm size distribution: Facts and theory,' American Economic Review, 93(4), 1075-1090.

Cohen, W.M. and D.A. Levinthal (1990), 'Absorptive capacity: A new perspective on learning and innovation,' Administrative Science Quarterly, 35(1), 128-152.

Collins, C.J. and K.G. Smith (2006), 'Knowledge exchange and combination: The role of human resource practices in the performance of high-technology firms,' Academy of Management Journal, 49(3), 544-560.

Collis, D.J. (1994), 'Research note: how valuable are organizational capabilities?' Strategic Management Journal, 15(S1), 143-152.

Crozier, M. (1964), The phenomenon of bureaucracy. University of Chicago Press: Chicago, IL.

Cyert, R.M. and J.G. March (1963), A behavioral theory of the firm. Prentice Hall: Englewood Cliffs, NJ.

Daft, R.L. and N.B. Macintosh (1981), 'A tentative exploration into the amount and equivocality of information processing in organizational work units,' Administrative Science Quarterly, 26(2), 207-224.

Damanpour, F. (1991), 'Organizational innovation: A meta-analysis of effects of determinants and moderators,' Academy of Management Journal, 34(3), 555-590.

Danneels, E. (2008), 'Organizational antecedents of second-order competences,' Strategic Management Journal, 29(5), 519-543.

Deshpande, R. and G. Zaltman, G. (1982), 'Factors affecting the use of market research information: A path analysis,' Journal of Marketing Research, 19(1), 14-31. 
Dewar, R.D., D.A. Whetten and D. Boje (1980), 'An examination of the reliability and validity of the Aiken and Hage scales of centralization, formalization, and task routineness,' Administrative Science Quarterly, 25(1), 120-128.

Drnevich, P.L. and A.P. Kriauciunas (2011), 'Clarifying the conditions and limits of the contributions of ordinary and dynamic capabilities to relative firm performance,' Strategic Management Journal, 32 (3), 254-279.

Easterby-Smith, M. and I.M. Prieto (2008), 'Dynamic Capabilities and Knowledge Management: An Integrative Role for Learning?’ British Journal of Management, 19, 235-249.

Echajari, L. and C. Thomas (2015), 'Learning from complex and heterogeneous experiences: the role of knowledge codification,' Journal of Knowledge Management, 19(5), 968986.

Edwards, J.R. (2001), 'Multidimensional constructs in organizational behavior research: An integrative analytical framework,' Organizational Research Methods, 4(2), 144-192.

Eggers, J. P. and S. Kaplan (2013), 'Cognition and capabilities: A multi-level perspective,' Academy of Management Annals, 7(1), 295-340.

Eisenhardt, K.M. and J. Martin (2000), 'Dynamic capabilities: What are they?' Strategic Management Journal, 21(10-11), 1105-1121.

Eisenhardt, K., N. Furr and C. Bingham (2010), 'Microfoundations of performance: Balancing efficiency and flexibility in dynamic environments,' Organization Science, 21(6), 1263-1273.

Feldman, M.S. and P.T. Pentland (2003), 'Reconceptualizing organizational routines as a source of flexibility and change,' Administrative Science Quarterly, 48(1), 94-118.

Fornell, C. and D.F. Larcker (1981), 'Evaluating structural equation models with unobservable variables and measurement error,' Journal of Marketing Research, 18(1), 39-50.

Foss, K. (2001), 'Organizing Technological Interdependencies: A Coordination Perspective on the Firm,' Industrial and Corporate Change, 10, 151-178.

Fourné, S.P.L., J.J.P. Jansen and T.J.M. Mom (2014), 'Strategic agility in MNEs: Managing tensions to capture opportunities across emerging and established markets,' California Management Review, 56(3), 13-38.

Galunic, D.C. and S. Rodan (1998), 'Resource recombinations in the firm: knowledge structures and the potential for schumpeterian innovation,' Strategic Management Journal, 19(12), 1193-1201.

Gersick, C.J. and J.R. Hackman (1990), 'Habitual routines in task-performing groups,' Organizational Behavior and Human Decision Processes, 47(1), 65-97.

Gilbert, C.G. (2005), 'Unbundling the structure of inertia, Resource versus routine rigidity,' Academy of Management Journal, 48, 741-763.

Grant, R.M. and G. Verona (2015), 'What's holding back empirical research into organizational capabilities? Remedies for common problems,' Strategic Organization, 13(1), 61-74.

Hage, J. and M. Aiken (1967), 'Relationship of centralization to other structural properties,' Administrative Science Quarterly, 12(1), 72-92. 
Hair, J.F., W.C. Black, B.J. Babin, and R.E. Anderson (2010), Multivariate data analysis. Prentice Hall: Upper Saddle River, NJ.

Hannan, M.T. and J. Freeman (1984), 'Structural inertia and organizational change,' American Sociological Review, 49(2), 149-164.

Hansen, M.T. (1999), 'The search-transfer problem: The role of weak ties in sharing knowledge across organization subunits,' Administrative Science Quarterly, 44(1), 82111.

Helfat, C.E. (1997), 'Know-how and asset complementarity and dynamic capability accumulation: The case of R\&D,' Strategic Management Journal, 18 (5), 339-360.

Helfat, C. E. and M.A. Peteraf (2015), 'Managerial cognitive capabilities and the microfoundations of dynamic capabilities,' Strategic Management Journal, 36(6), 831-850.

Holm, J. R., E. Lorenz, B. Å. Lundvall and A. Valeyre (2010), 'Organizational learning and systems of labor market regulation in Europe,' Industrial and Corporate Change, 19(4), 1141-1173.

Jansen, J.J.P., F.A.J. Van Den Bosch and H.W. Volberda (2005), ,Managing potential and realized absorptive capacity: How do organizational antecedents matter?' Academy of Management Journal, 48(6), 999-1015.

Jansen, J.J.P., F.A.J. Van Den Bosch and H.W. Volberda (2006), 'Exploratory innovation, exploitative innovation, and performance: Effects of organizational antecedents and environmental moderators,' Management Science, 52(11), 1661-1674.

Jaworski, B.J. and A.K. Kohli (1993), 'Market Orientation: Antecedents and Consequences,' Journal of Marketing, 57(7), 53-70.

Judge, W.Q. and A. Miller (1991), 'Antecedents and outcomes of decision speed in different environmental context,' Academy of Management Journal, 34(2), 449-463.

Khandwalla, P.N. (1977), The design of organizations. Harcourt Brace Jovanovich: New York, NY.

King, A.A. and C.L. Tucci (2002), 'Incumbent entry into new market niches: The role of experience and managerial choice in the creation of dynamic capabilities,' Management Science, 48(2), 171-186.

Kirschner, P.A. (2002), 'Cognitive load theory: Implications of cognitive load theory on the design of learning,' Learning and Instruction, 12(1), 1-10.

Kogut, B. and U. Zander (1992), 'Knowledge of the firm, combinative capabilities, and the replication of technology,' Organization Science, 3(3), 383-397.

Kor, Y.Y. and A. Mesko (2013), 'Dynamic managerial capabilities: Configuration and orchestration of top executives' capabilities and the firm's dominant logic,' Strategic Management Journal, 34(2), 233-244.

Kraatz, M.S. and E.J. Zajac (2001), 'How organizational resources affect strategic change and performance in turbulent environments: Theory and evidence,' Organization Science, $12(5), 632-657$.

Laamanen, T. and J. Wallin (2009), 'Cognitive dynamics of capability development paths,' Journal of Management Studies, 46(6), 950-981.

Leidner, R. (1993), Fast food, fast talk: Service work and the routinization of everyday life. University of California Press: Los Angeles, CA. 
Levinthal, D.A. and J.G. March (1993), 'The myopia of learning,' Strategic Management Journal, 14(S2), 95-112.

Leonard-Barton, D. (1992), 'Core capabilities and core rigidities: a paradox in managing new product development,' Strategic Management Journal, 13(S1), 111-125.

Levitt, B. and J.G. March (1988), 'Organizational learning,' Annual Review of Sociology, 14, 319-340.

Lin, X. and R. Germain (2003), 'Organizational structure, context, customer orientation, and performance: lessons from Chinese state-owned enterprises,' Strategic Management Journal, 24(11), 1131-1151.

Lyles, M.A. and C.R. Schwenk (1992), 'Top management, strategy and organizational knowledge structures,' Journal of Management Studies, 29(2), 155-174.

MacKenzie, S.B., P.M. Podsakoff and N.P. Podsakoff (2011), 'Construct measurement and validation procedures in MIS and behavioral research: Integrating new and existing techniques,' MIS Quarterly, 35(2), 293-334.

MacLean, D., R. MacIntosh and D. Seidl (2015), 'Rethinking dynamic capabilities from a creative action perspective,' Strategic Organization, 13(4), 340-352.

Malmi, T. and D.A. Brown (2008), 'Management control systems as a package Opportunities, challenges and research directions,' Management Accounting Research, 19(4), 287-300.

March, J.G. (1991), 'Exploration and Exploitation in Organizational Learning,' Organization Science, 2(1), 71-87.

Miles, R.E., C.C. Snow, A.D. Meyer and H.J. Coleman (1978), 'Organizational strategy, structure, and process,' Academy of Management Review, 3(3), 546-562.

Miller, D. (1988), 'Relating Porter's business strategies to environment and structure: Analysis and performance implications,' Academy of Management Journal, 31(2), 280-308.

Miner, A.S. (1990), 'Structural evolution through idiosyncratic jobs: The potential for unplanned learning,' Organization Science, 1, 195-210.

Mintzberg, H., B. Ahlstrand and J. Lampel (2005), Strategy Safari: A Guided Tour through the Wilds of Strategic Management. Simon and Schuster: New York, NY.

Mintzberg H. (1979), The Structuring of Organizations. Prentice-Hall: Englewood Cliffs, NJ.

Moch, M.K. and E.V. Morse (1977), 'Size, Centralization and Organizational Adoption of Innovations,' American Sociological Review, 42(5), 716-725.

Mooney, A.C., P.J. Holahan and A.C. Amason (2007), 'Don't take it personally: Exploring cognitive conflict as a mediator of affective conflict,' Journal of Management Studies, 44(5), 733-758.

Nelson, R.R. and S.G. Winter (1982), An evolutionary theory of economic change. Harvard University Press: Cambridge, MA.

Nickerson, J.A. and T.R. Zenger (2004), 'A knowledge-based theory of the firm - The problem-solving perspective,' Organization Science, 15(6), 617-632.

Nonaka, I. (1994), ‘A Dynamic Theory of Organizational Knowledge Creation,' Organization Science, 5(1), 14-37. 
Parmigiani, A. and J. Howard-Grenville (2011), 'Routines revisited: Exploring the capabilities and practice perspectives,' Academy of Management Annals, 5(1), 413453.

Pavlou, P.A. and O.A. El Sawy (2006), 'From IT leveraging competence to competitive advantage in turbulent environments: The case of new product development,' Information Systems Research, 17(3), 198-227.

Peteraf, M., G. Di Stefano and G. Verona (2013), 'The elephant in the room of dynamic capabilities: Bringing two diverging conversations together,' Strategic Management Journal, 34(12), 1389-1410.

Pisano, G. P. (2017), 'Toward a prescriptive theory of dynamic capabilities: connecting strategic choice, learning, and competition,' Industrial and Corporate Change, 26(5), 747-762.

Podsakoff, P.M., S.B. MacKenzie and N.P. Podsakoff (2012), 'Sources of method bias in social science research and recommendations on how to control it,' Annual Review of Psychology, 63, 539-569.

Prieto, I.M. and M. Easterby-Smith (2006), 'Dynamic capabilities and the role of organizational knowledge: An exploration,' European Journal of Information Systems, 15(5), 500-510.

Pugh, D.S., D.J. Hickson, C.R. Hinings and C. Turner (1968), 'Dimensions of organization structure,' Administrative Science Quarterly, 13(1), 65-105.

Rindova, V.P. and S. Kotha (2001), 'Continuous "morphing": Competing through dynamic capabilities, form, and function,' Academy of Management Journal, 44(6), 1263-1280.

Romme, A.G.L., E.P. Antonacopoulou, D.E. Mulders and M.S. Taylor (2012), 'The dynamism of organizational practices: the role of employment blueprints,' British Journal of Management, 23(4), 561-574.

Rueckert, R.W., O.C. Walker Jr. and K.J. Roering (1985), 'The organization of marketing activities: A contingency theory of structure and performance,' Journal of Marketing, 49(1), 13-25.

Schermelleh-Engel, K., H. Moosbrugger and H. Müller (2003), 'Evaluating the fit of structural equation models: Tests of significance and descriptive goodness-of-fit measures,' Methods of Psychological Research Online, 8(2), 23-74.

Schreyögg, G. and M. Kliesch-Eberl (2007), 'How dynamic can organizational capabilities be? Towards a dual-process model of capability dynamization,' Strategic Management Journal, 28(9), 913-933.

Schmitt, A., V.L. Barker, S. Raisch and D. Whetten (2015), 'Strategic Renewal in Times of Environmental Scarcity,' Long Range Planning, 49(3), 361-376.

Selznick, P. (1957), Leadership in Administration. Harper: New York, NY.

Senge, P.M. (2014), The dance of change: The challenges to sustaining momentum in a learning organization. Random House: New York, NY.

Shook, C.L., D.J. Ketchen, G.T.M. Hult and K.M. Kacmar (2004), 'An assessment of the use of structural equation modeling in strategic management research,' Strategic Management Journal, 25(4), 397-404.

Szulanski, G. (1996), 'Exploring internal stickiness: Impediments to the transfer of best practice within the firm,' Strategic Management Journal, 17, 27-43. 
Tallon, P.P. and A. Pinsonneault (2011), 'Competing perspectives on the link between strategic information technology alignment and organizational agility: insights from a mediation model,' MIS Quarterly, 35(2), 463-486.

Teece, D.J. (2000), 'Strategies for managing knowledge assets: the role of firm structure and industrial context,' Long Range Planning, 33(1), 35-54.

Teece, D.J. (2007), 'Explicating dynamic capabilities: the nature and microfoundations of (sustainable) enterprise performance,' Strategic Management Journal, 28(13), 13191350 .

Teece, D., M. Peteraf and S. Leih (2016), 'Dynamic capabilities and organizational agility,' California Management Review, 58(4), 13-35.

Teece, D. and G. P. Pisano (1994), 'The dynamic capabilities of firms: an introduction,' Industrial and Corporate Change, 3(3), 537-556.

Teece, D.J., G.P. Pisano and A. Shuen (1997), 'Dynamic capabilities and strategic management,' Strategic Management Journal, 18(7), 509-533.

Tippins, M.J. and R.S. Sohi (2003), 'IT competency and firm performance: is organizational learning a missing link?’ Strategic Management Journal, 24(8), 745-761.

Tushman, M.L. and P. Anderson (1986), 'Technological discontinuities and organizational environments,' Administrative Science Quarterly, 31(3), 439-465.

Volberda, H.W., C. Baden-Fuller and F.A.J. Van Den Bosch (2001), 'Mastering strategic renewal: Mobilising renewal journeys in multi-unit firms,' Long Range Planning, 34(2), 159-178.

Weick, K. E. (1979), 'Cognitive processes in organizations,' Research in Organizational Behavior, 1(1), 41-74.

Wilensky, H. (1967), Organizational Intelligence: Knowledge and Policy in Governmental and Industry. Basic Books: New York, NY.

Withey, M., R.L. Daft and W.H. Cooper (1983), 'Measures of Perrow's work unit technology: An empirical assessment and a new scale,' Academy of Management Journal, 26(1), 45-63.

Wong, C.S., K.S. Law and G.H. Huang (2008), 'On the importance of conducting constructlevel analysis for multidimensional constructs in theory development and testing,' Journal of Management, 34(4), 744-764.

Zahra, S.A., H.J. Sapienza and P. Davidsson (2006), 'Entrepreneurship and dynamic capabilities: a review, model and research agenda,' Journal of Management Studies, 43(4), 917-955.

Zollo, M. and S.G. Winter (2002), 'Deliberate learning and the evolution of dynamic capabilities,' Organization Science, 13(3), 339-351.

\section{APPENDIX}

Opportunity Recognition ( $\alpha=\mathbf{8 6}$ ) (7, "strongly agree", and 1, "strongly disagree")

We are quick to detect fundamental shifts in our industry (e.g. competition, technology, regulation).

We are good in identifying the likely effects of changes in our business environment on our business model.

We quickly understand new opportunities to serve our clients.

We are very good in observing and anticipating technological trends.

Capability Monitoring $(\boldsymbol{\alpha}=.87)$ (7, "strongly agree", and 1, "strongly disagree")

We regularly check the quality of our functional capabilities in comparison with competition.

We regularly check the quality of our functional capabilities in comparison with companies in different industries.

We pay a great attention on monitoring the change of functional capabilities. 
After changing existing capabilities or integrating new capabilities, we pay a great attention on monitoring the efficiency of new processes.

Knowledge Acquisition ( $\alpha=.81)$ (7, "strongly agree", and 1, "strongly disagree")

We frequently acquire knowledge about technologies and market trends from external sources.

We are able to identify and acquire external knowledge (e.g. market, technology) very quickly.

Employees of our unit regularly visit other branches to learn about new technologies, trends, or business models.

Knowledge Sharing ( $\alpha=$.77) (7, "strongly agree", and 1, "strongly disagree")

Existing knowledge (e.g. market or technology) is readily available to each department within our business unit.

Our business unit periodically circulates codified knowledge in form of documents (e.g., reports, newsletters) to update other departments.

When something important happens (market or technological development), the whole business unit knows about it in a short period.

Knowledge Creation ( $\alpha=.88$ ) (7, "strongly agree", and 1, "strongly disagree")

Our employees have the capabilities to produce many novel and useful ideas

Within this business unit, we have the capabilities successfully to learn new things.

We have the capabilities effectively to develop new knowledge or insights that have the potential to influence product

development.

To create new knowledge, our employees intensively use the experience of colleagues.

Capability Creation $(\alpha=.90)$ (7, "strongly agree", and 1, "strongly disagree")

We are effective in transforming existing knowledge into new functional capabilities.

Our employees introduce perceptible changes that enhance the effectiveness of existing capabilities.

Our employees are able to identify valuable capability elements, connect, and combine them in new ways.

We can effectively recombine existing capabilities into "novel" combinations.

Capability Integration ( $\alpha=.87$ ) (7, "strongly agree", and 1, "strongly disagree")

We are able to integrate new and existing ways of doing things without stifling their efficiency.

We can effectively integrate new externally sourced capabilities and combine them with existing capabilities into "novel" combinations.

We are very successfully in integrating newly acquired knowledge with existing knowledge.

Centralization $(\alpha=.93)$ (7, "strongly agree", and 1, "strongly disagree")

There can be little action taken here until a supervisor approves a decision.

Even small matters have to be referred to someone higher up for a final decision.

Most decisions people make here have to have their supervisor's approval.

Routinization ( $\alpha=.91$ ) (7, "strongly agree", and 1, "strongly disagree")

Most of the tasks are the same from day-to-day.

People in this unit do about the same job in the same way most of the time.

Basically, unit members perform repetitive activities in doing their jobs.

Duties in this business unit are very repetitious.

Formalization ( $\alpha=.69)$ (7, "strongly agree", and 1, "strongly disagree")

Whatever situation arises, written procedures are available for dealing with it.

Rules and procedures occupy a central place in the organization.

Written records are kept of everyone's performance.

Written job descriptions are formulated for positions at all levels in the organizational unit.

Slack Resources $(\alpha=.72)$ (7, "strongly agree", and 1, "strongly disagree")

My business unit has a reasonable amount of resources in reserve.

We have ample discretionary financial resources.

We can always find the 'manpower' to work on special projects.

Corporate Support (1, "never", 2, "rarely", 3, "sometimes", and 4, “often")

How often has your business unit used the support of specialized, internal departments, e.g. staff divisions or corporate center, for projects regarding strategic renewal or corporate development during the last three years? 
FIGURE 1: Second-order Measurement Model of Dynamic Capabilities

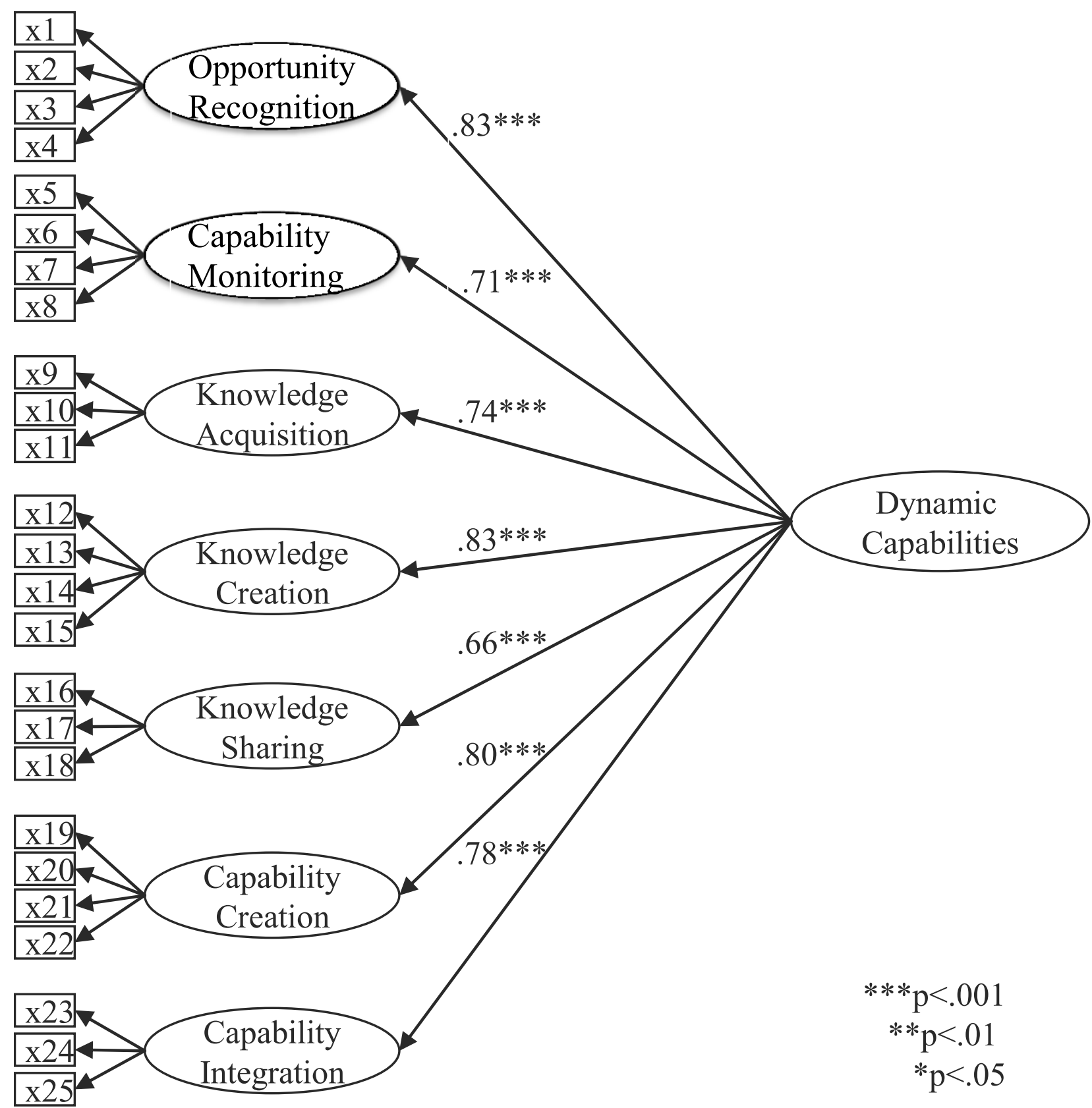


TABLE 1: Results of the Exploratory Factor Analysis of all Variables

\begin{tabular}{|c|c|c|c|c|c|c|c|c|c|c|}
\hline Variables & $\begin{array}{l}\text { Opportunity } \\
\text { Recognition }\end{array}$ & $\begin{array}{l}\text { Capability } \\
\text { Monitoring }\end{array}$ & $\begin{array}{c}\text { Knowledge } \\
\text { Creation }\end{array}$ & $\begin{array}{l}\text { Knowledge } \\
\text { Acquisition }\end{array}$ & $\begin{array}{c}\text { Knowledge } \\
\text { Sharing }\end{array}$ & $\begin{array}{c}\text { Capability } \\
\text { Creation }\end{array}$ & $\begin{array}{c}\text { Capability } \\
\text { Integration }\end{array}$ & Formalization & Centralization & Routinization \\
\hline Item 1 & .75 & .20 & .11 & .11 & .16 & .14 & .28 & .05 & -.08 & -.06 \\
\hline Item 2 & .63 & .23 & .21 & .20 & .18 & .15 & .09 & -.04 & -.13 & -.06 \\
\hline Item 3 & .62 & .23 & .20 & .10 & .19 & .18 & .26 & .03 & -.16 & -.08 \\
\hline Item 4 & .47 & .30 & .18 & .20 & .12 & .23 & .13 & .05 & -.02 & -.06 \\
\hline Item 5 & .14 & .85 & .15 & .12 & .14 & .15 & .14 & .13 & -.05 & .04 \\
\hline Item 6 & .19 & .69 & .09 & .12 & .15 & .25 & .17 & .12 & -.02 & .00 \\
\hline Item 7 & .14 & .66 & .09 & .16 & .19 & .19 & .11 & .12 & -.11 & -.01 \\
\hline Item 8 & .25 & .63 & .13 & .30 & .08 & .07 & .01 & .00 & -.04 & -.01 \\
\hline Item 9 & .22 & .14 & .68 & .23 & .12 & .23 & .13 & .17 & -.10 & -.08 \\
\hline Item 10 & .24 & .21 & .66 & .19 & .13 & .23 & .18 & .06 & -.12 & -.23 \\
\hline Item 11 & .15 & .12 & .64 & .20 & .08 & .21 & .13 & .16 & -.11 & -.07 \\
\hline Item 12 & .09 & .18 & .57 & .17 & .30 & .32 & .22 & .07 & -.08 & -.10 \\
\hline Item 13 & .11 & .23 & .19 & .71 & .08 & .08 & .11 & .10 & -.02 & -.05 \\
\hline Item 14 & .32 & .25 & .26 & .64 & .08 & .12 & .11 & .03 & -.03 & -.22 \\
\hline Item 15 & .12 & .25 & .21 & .53 & .18 & .13 & .12 & .07 & -.03 & -.12 \\
\hline Item 16 & .21 & .19 & .06 & -.01 & .71 & .11 & .08 & .12 & -.03 & -.10 \\
\hline Item 17 & .11 & .18 & .10 & .12 & .67 & .08 & .13 & .13 & -.09 & -.06 \\
\hline Item 18 & .10 & .08 & .19 & .16 & .58 & .19 & .14 & .06 & -.13 & -.03 \\
\hline Item 19 & .09 & .15 & .23 & .16 & .14 & .79 & .17 & .12 & -.11 & -.07 \\
\hline Item 20 & .16 & .19 & .18 & .05 & .18 & .75 & .27 & .00 & -.13 & -.10 \\
\hline Item 21 & .20 & .21 & .23 & .07 & .05 & .68 & .17 & .17 & -.11 & -.06 \\
\hline Item 22 & .25 & .34 & .19 & .09 & .18 & .58 & .29 & .02 & -.08 & .01 \\
\hline Item 23 & .24 & .17 & .16 & .10 & .13 & .23 & .75 & .08 & -.13 & -.03 \\
\hline Item 24 & .17 & .17 & .17 & .11 & .11 & .27 & .68 & .04 & -.02 & -.01 \\
\hline Item 25 & .24 & .08 & .18 & .16 & .25 & .30 & .63 & .15 & -.14 & -.02 \\
\hline Item 26 & -.05 & .04 & .03 & -.02 & -.08 & .14 & .06 & .75 & .25 & .23 \\
\hline Item 27 & -.04 & .07 & -.03 & .00 & .05 & .08 & .06 & .65 & .08 & .32 \\
\hline Item 28 & .02 & .10 & .11 & .06 & .14 & -.01 & .00 & .47 & .07 & -.05 \\
\hline Item 29 & .08 & .04 & .10 & .07 & .09 & .04 & .05 & .41 & .05 & -.09 \\
\hline Item 30 & -.09 & -.03 & -.09 & .01 & -.08 & -.10 & -.07 & .14 & .88 & .15 \\
\hline Item 31 & -.11 & -.09 & -.07 & -.07 & -.08 & -.13 & -.11 & .08 & .88 & .11 \\
\hline Item 32 & -.06 & -.08 & -.12 & -.02 & -.07 & -.07 & -.02 & .30 & .80 & .20 \\
\hline Item 33 & .01 & -.02 & -.09 & -.11 & -.07 & -.09 & -.08 & .03 & .10 & .89 \\
\hline Item 34 & -.07 & .03 & -.09 & -.09 & -.06 & -.07 & .00 & .00 & .13 & .85 \\
\hline Item 35 & .00 & -.04 & -.07 & -.06 & .00 & -.03 & -.01 & .06 & .11 & .81 \\
\hline Item 36 & -.09 & .01 & -.02 & .00 & -.06 & .00 & .02 & .10 & .05 & .78 \\
\hline
\end{tabular}


TABLE 2: Descriptive Statistics and Pearson Correlations

\begin{tabular}{|c|c|c|c|c|c|c|c|c|c|c|c|c|c|c|c|c|c|c|c|c|c|c|c|c|c|}
\hline Variables & Mean & s.d. & 1 & 2 & 3 & 4 & 5 & 6 & 7 & 8 & 9 & 10 & 11 & 12 & 13 & 14 & 15 & 16 & 17 & 18 & 19 & 20 & 21 & 22 & 23 \\
\hline 1 Dynamic Capabilities & 4.69 & .93 & & & & & & & & & & & & & & & & & & & & & & & \\
\hline 2 Opportunity Recognition & 4.82 & 1.19 & $.81^{\cdots}$ & & & & & & & & & & & & & & & & & & & & & & \\
\hline 3 Capability Monitoring & 4.10 & 1.37 & $.77^{* * *}$ & $.57^{* \cdots+}$ & & & & & & & & & & & & & & & & & & & & & \\
\hline 4 Knowledge Acquisition & 4.78 & 1.26 & $.73^{\cdots}$ & .54 & $.54^{\cdots * *}$ & & & & & & & & & & & & & & & & & & & & \\
\hline 5 Knowledge Sharing & 4.34 & 1.39 & $.67^{\cdots *}$ & $.47^{\cdots+}$ & .42 & $.38^{\cdots *}$ & & & & & & & & & & & & & & & & & & & \\
\hline 6 Knowledge Creation & 5.23 & 1.10 & $.80^{\cdots *}$ & $.57^{\cdots \cdots}$ & $.48^{\cdots \cdots}$ & $.59^{* \cdots}$ & $.46^{\cdots+}$ & & & & & & & & & & & & & & & & & & \\
\hline 7 Capability Creation & 4.70 & 1.16 & $.80^{\cdots}$ & $.57^{+\cdots+}$ & $.53^{m * *}$ & $.43^{* *}$ & $.43^{*+*+}$ & $.63^{\cdots}$ & & & & & & & & & & & & & & & & & \\
\hline 8 Capability Integration & 4.84 & 1.05 & $.74^{\cdots \cdots}$ & $.58^{* * *}$ & $.43^{\cdots \cdots+}$ & $.43^{* * *}$ & $.43^{* *+*}$ & $.55^{\cdots+}$ & $.63^{\cdots+}$ & & & & & & & & & & & & & & & & \\
\hline 9 Corporate Support & 3.10 & .96 & .10 & .02 & .11 & $.17^{* \prime}$ & .10 & .07 & -.01 & .07 & & & & & & & & & & & & & & & \\
\hline 10 Firm Size (log) & 3.21 & 1.08 & -.04 & -.07 & .04 & -.03 & -.06 & .00 & -.07 & -.08 & $.14^{*}$ & & & & & & & & & & & & & & \\
\hline 11 Firm Age (log) & 1.30 & .54 & .01 & .06 & .03 & .02 & -.06 & .05 & -.02 & -.01 & -.01 & $.38^{* * *}$ & & & & & & & & & & & & & \\
\hline 12 Slack Resources & 3.36 & 1.32 & $.19^{*}$ & $.15^{*}$ & $.18 *$ & $.14^{*}$ & .09 & $.15^{\circ}$ & $.16^{*}$ & $.15^{\circ}$ & $.16^{*}$ & .08 & .00 & & & & & & & & & & & & \\
\hline 13 Telecommunication & .08 & .28 & -.11 & -.09 & -.04 & -.06 & -.06 & -.11 & -.12 & -.12 & -.03 & .08 & $-.18 *$ & $-.16^{*}$ & & & & & & & & & & & \\
\hline 14 Automobile & .13 & .34 & .04 & .02 & .03 & .01 & .01 & .04 & .10 & .01 & .02 & .11 & .04 & -.05 & -.12 & & & & & & & & & & \\
\hline 15 Computer/IT & .08 & .28 & .09 & .00 & .10 & .05 & $.17^{*}$ & .00 & .09 & .06 & -.10 & .09 & -.01 & -.03 & -.09 & -.12 & & & & & & & & & \\
\hline 16 Banking/Insurance & .09 & .28 & .07 & -.02 & .04 & .08 & .10 & .10 & -.01 & $.15^{\circ}$ & $.16^{*}$ & $-.20^{*=5}$ & $-.13^{*}$ & -.03 & -.09 & -.12 & -.09 & & & & & & & & \\
\hline 17 Energy & .07 & .25 & -.06 & -.02 & -.05 & -.03 & -.04 & -.05 & -.09 & -.03 & .05 & -.05 & -.05 & $.14^{\circ}$ & -.08 & -.11 & -.08 & -.08 & & & & & & & \\
\hline $18 \mathrm{Chemicals/Pharmaceuticals}$ & .09 & .29 & -.09 & -.03 & $-.13^{*}$ & -.12 & .01 & -.09 & -.05 & -.10 & -.03 & .09 & .12 & .03 & -.10 & $-.13^{*}$ & -.10 & -.10 & -.09 & & & & & & \\
\hline 19 Machinery & .12 & .32 & -.06 & -.01 & -.10 & -.08 & -.10 & -.02 & .03 & -.06 & -.11 & -.08 & .04 & -.06 & -.11 & $-.14^{*}$ & -.11 & -.11 & -.10 & -.12 & & & & & \\
\hline 20 Transport and Services & .08 & .27 & .03 & .05 & .05 & -.01 & .03 & .08 & -.04 & .02 & .09 & .01 & .00 & $.13^{*}$ & -.09 & -.11 & -.09 & -.09 & -.08 & -.09 & -.11 & & & & \\
\hline 21 Consumer & .11 & .31 & -.04 & -.04 & .01 & -.08 & -.10 & -.04 & -.01 & .04 & .06 & .06 & .04 & .04 & -.10 & $-.13^{*}$ & -.10 & -.11 & -.09 & -.11 & $-.13^{*}$ & -.10 & & & \\
\hline 22 Formalization & 4.87 & 1.19 & $.22 \cdots$ & .09 & $.20 \cdots$ & $.14^{*}$ & $.18^{* *}$ & $.20 *$ & $.18^{*}$ & $.177^{*}$ & .09 & $.17^{*}$ & .04 & .01 & -.09 & .26 & -.06 & .05 & -.06 & .00 & -.07 & -.01 & -.02 & & \\
\hline 23 Centralization & 3.79 & 1.66 & $-.31 *$ & $-.29 \cdots$ & $-.18 *$ & $-.17^{* *}$ & -.22 & $-.28 \cdots$ & $-.28 \cdots$ & $-.25 \cdots$ & .06 & .10 & .01 & -.04 & .07 & .10 & $-.12 *$ & -.05 & .09 & .02 & -.04 & -.07 & .03 & $.27^{m *}$ & \\
\hline 24 Routinization & 3.54 & 1.35 & $-.21^{m *}$ & $-.17^{* *}$ & -.06 & $-.25^{m}$ & $-.16^{\prime *}$ & -.25 & $-.16^{* *}$ & -.11 & -.05 & $.24^{*+*}$ & $.15^{\circ}$ & -.01 & -.01 & .07 & .02 & -.08 & -.01 & -.07 & .01 & .05 & .12 & $.18^{* \prime}$ & $.29^{\prime \prime}$ \\
\hline \\
\hline \multicolumn{26}{|l|}{$\cdots p<0.001$} \\
\hline \multicolumn{26}{|l|}{$" \mathrm{p}<0.01$} \\
\hline $\mathrm{p}<0.05$ & & & & & & & & & & & & & & & & & & & & & & & & & \\
\hline
\end{tabular}


FIGURE 2: Results of SEM Analysis with Dynamic Capabilities and Components as

\section{Dependent Variables}

Model A1

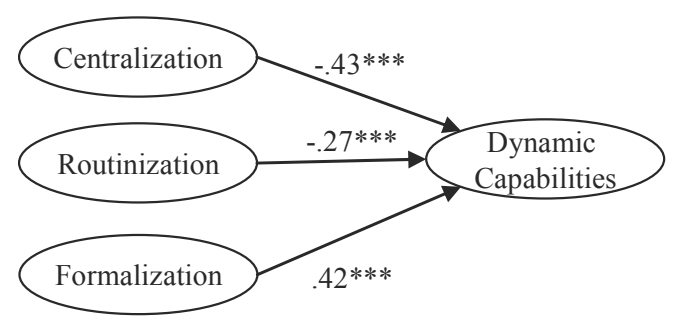

Model A3

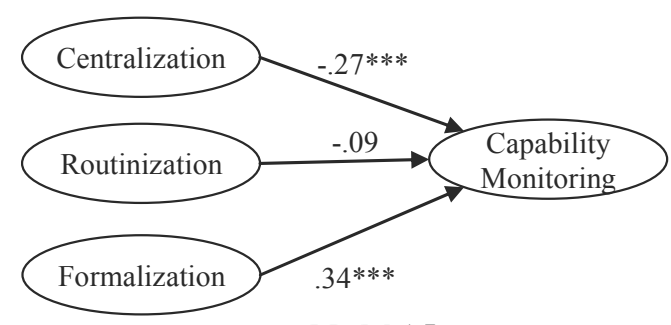

Model A5

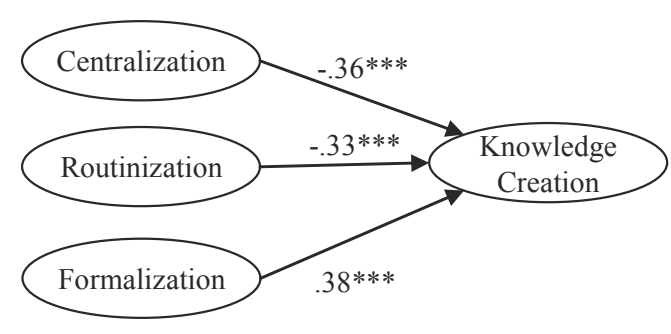

Model A7

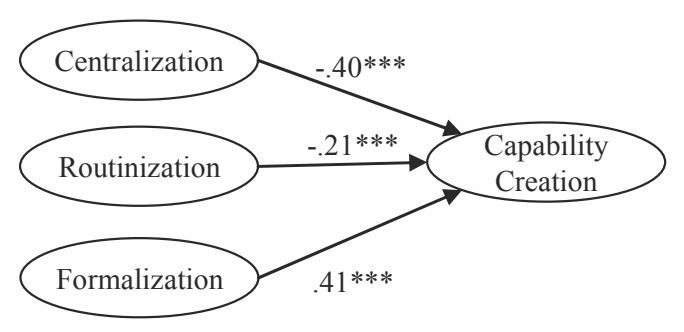

Model A2

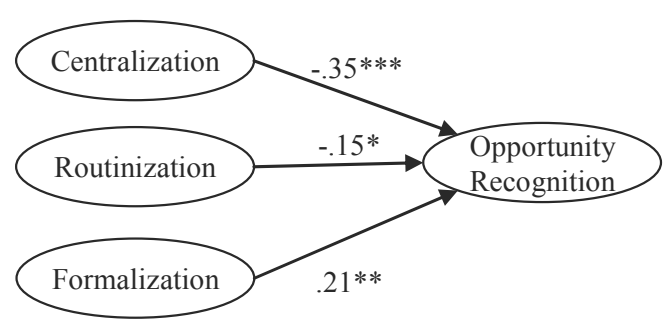

Model A4

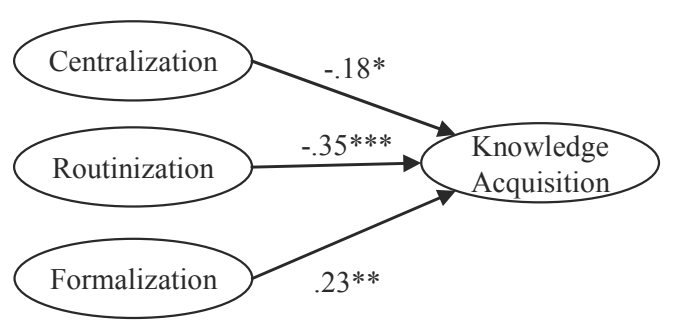

Model A6

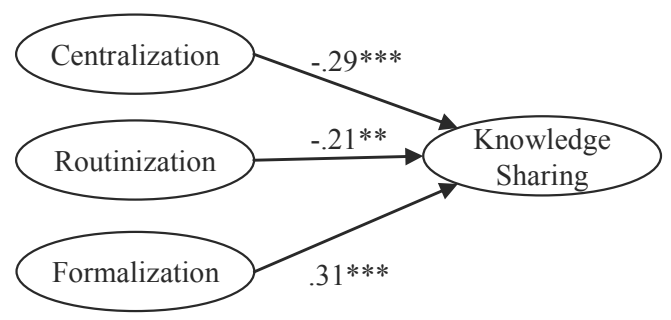

Model A8

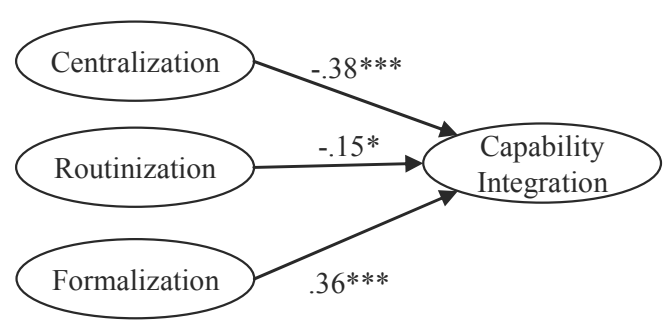

$* * * \mathrm{p}<.001 ; * * \mathrm{p}<.01 ; * \mathrm{p}<.05$ 